\title{
A new very high-resolution climatological dataset in Portugal: Application to hydrological modeling in a mountainous watershed
}

\author{
A.R. Fonseca*, J.A. Santos \\ Centre for the Research and Technology of Agro-environmental and Biological Sciences, CITAB, Universidade de Trás-os-Montes e Alto Douro, UTAD, 5000-801, Vila Real, \\ Portugal
}

\section{A R T I C L E I N F O}

\section{Keywords:}

Distributed hydrologic model

Statistical downscaling

High-resolution climatic data

Corgo river

Portugal

\begin{abstract}
A B S T R A C T
The study of precipitation and temperature variability in Portugal, including their extremes, is often restricted by the lack of high-resolution gridded datasets at daily timescales and available for sufficiently long time periods. They are of quite importance specially when considering hydrology modeling at a local scale. To overcome this limitation, we develop new high-resolution gridded datasets $(\sim 1 \mathrm{~km})$ of daily precipitation (1950-2015) over Portugal. Daily precipitation is downscaled by ordinary kriging from a coarser gridded dataset $(\sim 20 \mathrm{~km})$. Daily temperatures were retrieved from a previous work and extracted for the target watershed in this study, Corgo River (northern Portugal). The aim of the present study was to investigate the potential of the new high-resolution data in improving the performance of a distributed hydrologic model, Hydrological Simulation Program - FORTRAN (HSPF) in simulating flowrates at one target watershed in northern Portugal (Corgo River watershed), thus providing a practical basis for subsequent hydrological analysis. The performances of the HSPF model, driven by either a single weather station or the new gridded datasets are compared. The results clearly hint at an improved model performance when using our dataset (Nash-Sutcliffe coefficient of efficiency at daily timescale: 0.34 for the single-station run and 0.64 for the multi-point run). A good performance was also found in reproducing specific flash flood events. Although the advantage of using these novel climatic datasets for hydrologic modeling in Portugal is demonstrated herein, they can be applied to other areas of research, such as ecology, agriculture and forestry, contributing to more accurate decision support systems to assist decisionmakers and stakeholders.
\end{abstract}

\section{Introduction}

The recurrent lack of reliable, consistent and homogeneous atmospheric data, available over several decades, is a common shortcoming for hydrologic modeling (Schuol and Abbaspour, 2007; Shrestha et al., 2004). The challenge lies in obtaining reliable weather/climate input data (Kouwen et al., 2004; Mehta et al., 2004), which is usually one of the most important drivers of hydrologic models (Bleecker et al., 1995; Obled et al., 1994). Assessing the performance of hydrologic models is also difficult due to the lack of observed streamflow data (Hughes and Slaughter, 2015). Their application to a given watershed usually relies on a few weather stations, which are occasionally sparsely distributed and cannot fully represent the climate conditions/gradients within that watershed. Moreover, observed temporal variability in hydrological parameters may not be properly represented due to atmospheric forcing uncertainties (Ciach, 2003; White et al., 2014).

In watersheds characterized by complex orography and strong climate gradients it is particularly important to input hydrologic models with accurate and very high-resolution atmospheric datasets (El-Sadek et al., 2011). Specially, when evaluating daily or sub-daily data specifically under a future climate change context. In Portugal, several studies have been keen to hydrologic modeling for a wide range of river watersheds, but the meteorological data is typically obtained from either a single weather station or a relatively sparse meteorological network (Azorin-Molina et al., 2014; Fonseca et al., 2014, 2016, 2017; Tavares Wahren et al., 2016; Vieira et al., 2012, 2013).

Several previous studies have demonstrated the key role played by the large-scale atmospheric circulation on both precipitation (e.g. Costa et al., 2012; Fragoso et al., 2015; Santos et al., 2007; Santos et al., 2005; Santos et al., 2016) and temperature (e.g. Andrade et al., 2014; Andrade et al., 2012; Santos and Corte-Real, 2006; Santos et al., 2015a) variability and their extremes in Portugal, namely the role of different jet stream regimes in triggering extreme near-surface conditions over Portugal (Santos et al., 2013). Furthermore, long records of historical floods in Portugal highlight their strong connection to large-scale atmospheric forcing (Santos et al., 2015a). However, the complex

\footnotetext{
* Corresponding author.

E-mail address: andre.fonseca@utad.pt (A.R. Fonseca).
} 
orography, the distance to the coastline and latitudinal variation, in the transition between the climatological Azores high and the subpolar North Atlantic low pressure systems, amongst other drivers, significantly enhance regional differences. These features underlie the strong spatial gradients in both precipitation and temperature fields (Costa et al., 2016), thus highlight the need for developing very highresolution datasets for regional-to-local scale assessments (e.g. at a river watershed scale).

The aim of the present study is to investigate the potential of the new very high-resolution data in improving the performance of a distributed hydrologic model (Hydrological Simulation Program FORTRAN, HSPF henceforth) in simulating flowrates at one target watershed in northern Portugal (Corgo River watershed), thus providing a practical basis for subsequent hydrological analysis. In section 2 , the datasets and the applied methodologies will be presented. The main results are presented and discussed in Section 3 and the conclusions are outlined in Section 4.

\section{Materials and methods}

\subsection{Hydrological model}

The hydrological model Hydrologic Simulation Program FORTRAN (HSPF) was used in this study. HSPF is based on the original Stanford Watershed Model IV (Crawford and Linsley, 1966) and is a compilation of three formerly well-established models: Agricultural Runoff Management Model (ARM) (Donigian and Davis, 1978), Non-point Source Runoff Model (NPS) (Donigian and Crawford, 1976) and Hydrological Simulation Program (HSP) including HSP Quality (Donigian and Huber, 1991; Donigian et al., 1995). HSPF is a semi-distributed model that simulates water and contaminant transport over spatially distributed areas within a watershed. It simulates hydrological, hydraulic and water quality processes, in streams and on pervious and impervious land surfaces, on a continuous basis (Bicknell et al., 2001). The application of HSPF to model water quantity and quality has been reported in several studies (Bergman et al., 2002; Fonseca et al., 2014, 2015, 2016; Lian et al., 2007; Zhang et al., 2009). A list of hydrology and hydraulic parameters and the corresponding recommended value ranges, can be found in WATERSHEDS Technical Note 6 (Bicknell, 2000).

\subsection{Study area}

In order to test the added-value of using the new climatic dataset, when compared to the more conventional approach of using a single meteorological station, the HSPF was run to model the hydrology of the Corgo River watershed, in Northern Portugal (Fig. 1a). As one of Douro River tributaries, it covers an area of approximately $462 \mathrm{~km}^{2}$ and flows across the city of Vila Real (Fig. 1a). As the observed daily mean flowrate data, recorded at the Ermida-Corgo hydrometric station, is only available for model calibration over the period of 1956-2003, the HSPF simulation was carried out only for this period.

\subsection{Datasets}

\subsubsection{CORINE Land Cover and digital elevation model}

A high-resolution digital elevation model, GTOPO30 digital elevation dataset (https://1ta.cr.usgs.gov/GTOPO30), was used to delineate the watershed (Fig. 1b). The CORINE Land Cover 2006 (CLC2006) raster data were retrieved from the European Environment Agency (EEA, http://www.eea.europa.eu). Land use was aggregated into five main categories, according to CLC2006 nomenclature (Urban or Builtup Area, Forest Land, Agricultural Land, Barren Land and Wetlands) so as to simplify the modeling process (Fig. 1c).

\subsubsection{Precipitation}

Gridded daily precipitation totals at $\sim 20 \mathrm{~km}$ spatial resolution (PT02 database) supplied by the Portuguese Weather Service (IPMA, www.ipma.pt), are available for Portugal spanning a period of 1950-2003 with continuous and homogeneous precipitation data (BeloPereira et al., 2011). PT02 comprises a high number of weather stations over Portugal, more than other existing daily gridded precipitation datasets (i.e. E-OBS gridded dataset) (Haylock et al., 2008, Hofstra et al., 2009), thus being used for the present study (hydrological models strongly rely on precipitation data). For the remaining period of 2004-2015, the daily precipitation fields were calculated by multiplying the E-OBS daily fields (previously interpolated to the same spatial resolution) with the ratio between the yearly sum of PT02 and EOBS over their common period of 1950-2003. The resulting gridded precipitation dataset comprise the period of 1950-2015 (Fig. S1) (PT.P.HRES henceforth). Gridded daily precipitation fields were bilinearly interpolated (on latitude and longitude coordinates) to a $1 \mathrm{~km}$ grid resolution for the whole dataset covering mainland Portugal and were then retrieved within the Corgo River watershed. This interpolation allows greater detail on the precipitation data for hydrological modelling.

\subsubsection{Temperature}

High-resolution $(\sim 1 \mathrm{~km})$ daily mean, minimum and maximum temperatures over main land Portugal (PT.TG.HRES, PT.TN.HRES and PT.TX.HRES) over the period of 1950-2015 were retrieved for the Corgo River watershed. The methodology followed to obtain this gridded datasets, their validation and characterization can be found in Fonseca and Santos (2017).

\subsection{Model calibration and validation}

Flowrate was calibrated for the hydrological years of 1956-1976 and validated for the period of 1978-2003. Model validation was performed only when model calibration goodness-of-fit was acceptable. Efficiency assessment was also determined for the model validation output data. Considering a 20-year calibration period and 25-year validation period, it is reasonable to assume that the model incorporates the main hydrological trends. The performance of the model was assessed by three statistical methods: Deviation Runoff $(D v)$, NashSutcliffe model efficiency coefficient (E) (Nash and Sutcliffe, 1970) and the Coefficient of Determination $\left(R^{2}\right)$. The study of Donigian (2002) suggests ranges of the coefficient of determination $\left(R^{2}\right)$ for daily and monthly flow. For daily flows, $R^{2}$ is considered to be poor when it is less than 0.6 , fair between 0.6 and 0.7 , good between 0.7 and 0.8 , and very good when above 0.8 . On the other hand, for monthly flows, $R^{2}$ is considered very good when above 0.85 , good for values between 0.75 and 0.85 , fair between 0.65 and 0.75 and poor below 0.65 . Concerning the deviation of volumes $(D v)$, a good calibration is achieved for values between $-15 \%$ and $15 \%$, and values of Nash-Sutcliffe model efficiency coefficient $(E)$ above 0.6 and 0.8 for daily and monthly simulations, respectively (Duncker and Melching, 1998).

The model was segmented according to each sub-watershed ( $n=50$ ), where 50 hydrologic response units were considered, with their own unique time series of temperature and precipitation, derived from the average of all grid boxes enclosed by each sub-watershed. The estimation of the potential evapotranspiration (PET) in HSPF is based on the Penman-Monteith equation (Penman, 1948) and on the method of Kohler et al. (1955). The PET time series are calculated within the Watershed Data Management Utility (WDMUtil, BASINS platform plugin), which is a tool for managing watershed modeling time-series data (Hummel et al., 2001). For a sensitivity analysis, flowrate was also calibrated with local data to examine the response of the model against the new very high-resolution climatic data. For this purpose, a single meteorological station (Vila Real) was considered for the entire watershed, with records of precipitation and temperature available for the 

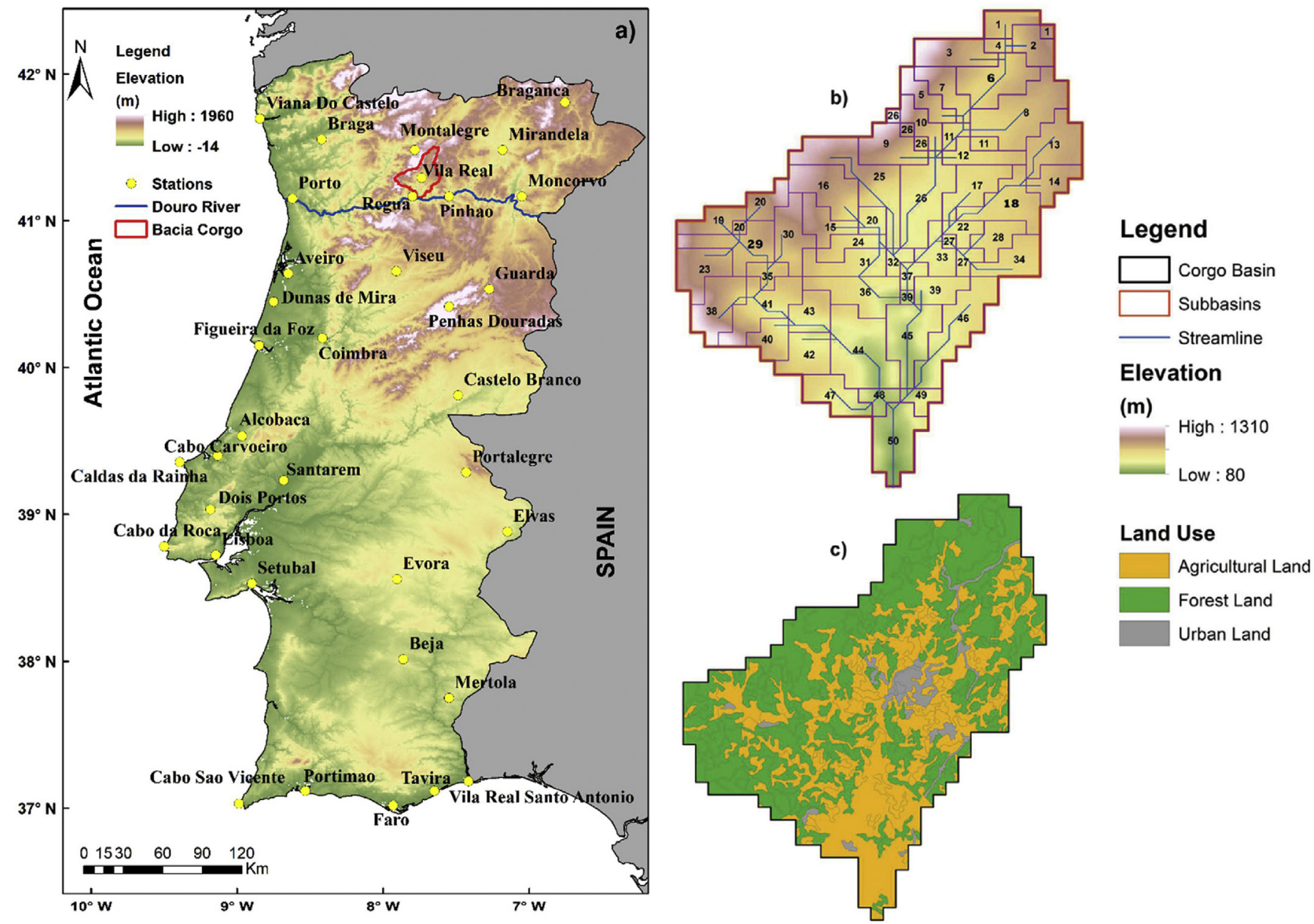

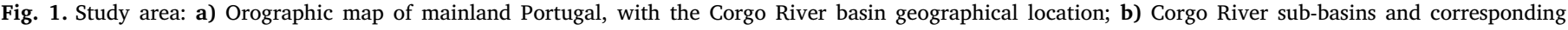
streamlines, achieved through delineation of the digital elevation map to be used in the hydrological model; c) Corgo River Land use distribution.

modeling period (1956-2003), and a new calibration of the model was performed. To perform the calibration we first calibrate the total runoff volume in the watershed followed by the annual, seasonal and monthly volumes, by adjusting the corresponding model parameters within literature values. Further, we look at the hydrographs and start calibrating hydrograph shape and peak flows. The calibration is considered satisfactory when the criteria selected previously show good agreement between observed and simulated flow.

As a complementary analysis, four flash flood events registered in the Corgo River watershed, previously identified by Santos et al. (2017b), were selected to assess the response of the hydrological model (HSPF) under these extreme conditions. Although these events are commonly very difficult to simulate, owing to a large number of triggering factors that need to be properly taken into consideration (i.e. geographical and environmental features, such as watershed morphology and spatial and temporal distribution of rainfall). The ability of the model to capture these extreme episodes is critical for an adequate monitoring of flowrates and for flood risk assessments under different circumstances.

\section{Results and discussion}

\subsection{Hydrologic simulation for the Corgo watershed}

For the Corgo River watershed, and based on the records from the Ermida-Corgo station, the medians of the daily mean flowrates vary from $11.7 \mathrm{~m}^{3} \mathrm{~s}^{-1}$, in January, to $0.07 \mathrm{~m}^{3} \mathrm{~s}^{-1}$, in August, while their full range is from 0 to $240 \mathrm{~m}^{3} \mathrm{~s}^{-1}$ (Fig. S2). Further, there is still a high variability and positive skewness in their monthly empirical distributions (Fig. S2). Hence, the observed daily mean flowrates hint at strong seasonality and irregularity, peaking in winter and with very pronounced maximum flowrates, which are indeed typical of the Mediterranean-type flow regimes (high torrentiality). This flowrate regime is in clear agreement with the monthly distributions of daily precipitation (Fig. S3) within this specific watershed. The corresponding monthly distributions of daily mean temperatures also show a strong solardriven seasonality, but with much more symmetric distributions (Fig. S4).

The values of the hydrologic parameters for the model calibration were within the range of those presented in literature (Bicknell, 2000) (Table S1). Model calibration/validation were achieved when statistical criteria values were within those presented in literature (Duncker and Melching, 1998). The model validation consisted in simulating the validation period (1978-2003) with the application of the same parameter sets as in calibration. An acceptable validation is achieved if the statistical results from validation were also considered within the ranges defined in the literature.

The HSPF model performed well with respect to the simulation of river flow in the Corgo River, for both daily (Fig. 2) and monthly (Fig. 3) timescales, since the fits between observed and simulated flows present high coefficients of determination $\left(R^{2}\right)$, particularly at the monthly time step. The coefficients of determination also confirm the goodness-of-fit of the model, with very good performance $(>0.8)$ for all model runs, except for the daily validation, for which only a good 

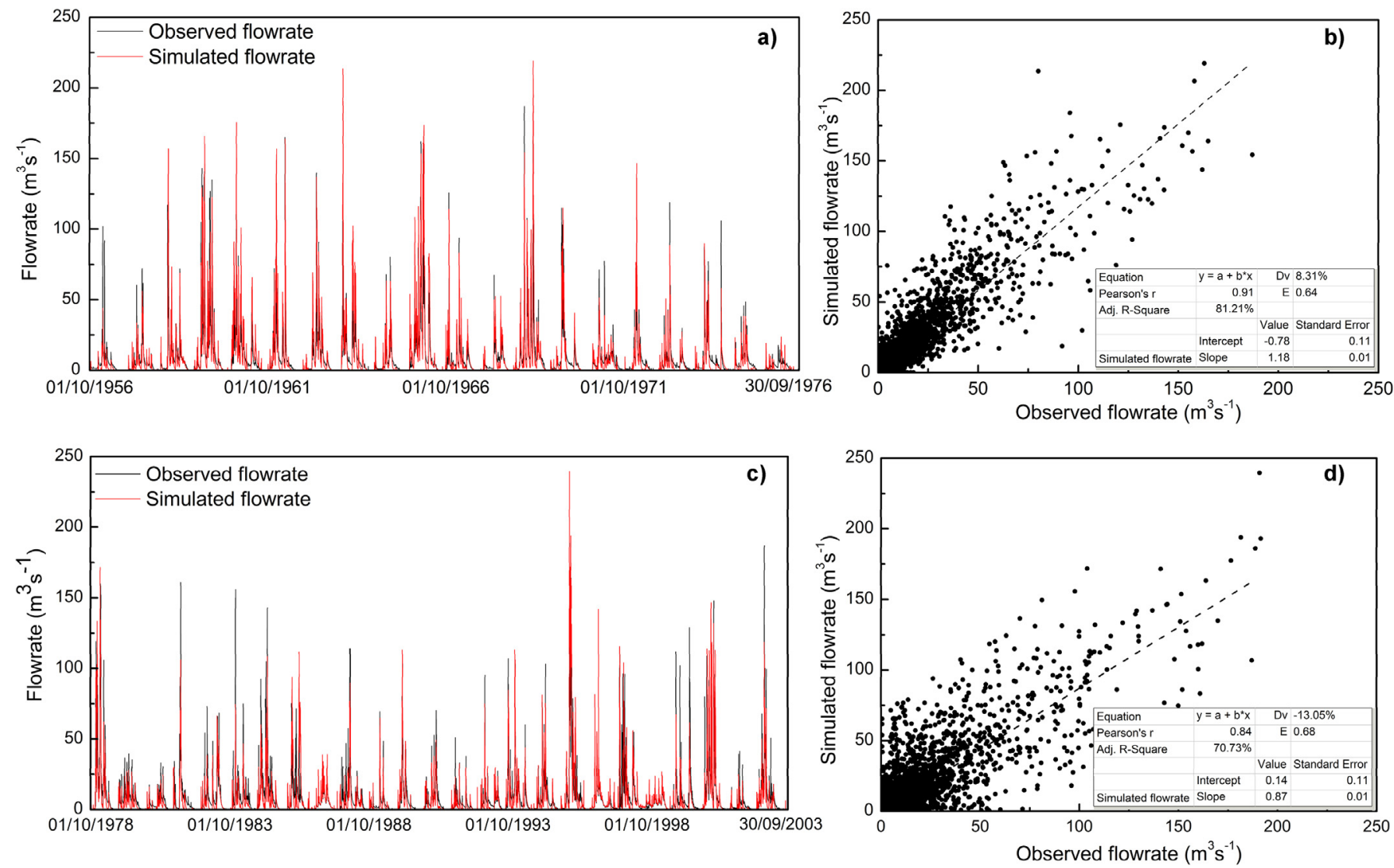

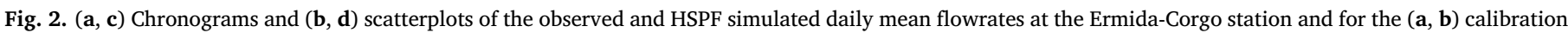
and $(\mathbf{c}, \mathbf{d})$ validation periods.

performance is achieved (0.71). The Nash-Sutcliffe model efficiency coefficient achieved very good results as well, with the lowest value (0.64) of model efficiency occurring during the daily calibration phase. Even though values of $E$ slightly increased from the calibration to the validation phase, for both daily and monthly time steps, the simulated flow at the validation phase was underestimated by approximately $13 \%$ (overestimated by $8 \%$ in the calibration period).

A close inspection of Figs. 2 and 3 , as well as considering the achieved values of the statistical criteria, indicates that the best-fit calibration parameter sets provide an acceptable simulation of precipitation-flowrate relation for the Corgo River watershed and over a wide range of hydrologic conditions. Also confirmed by the simulated hydrograph shape and peaks which, show a very good representation of the observed flow at the Corgo River station. According to the literature presented earlier in section 2.3, both calibration and simulation periods performed very satisfactorily regarding the deviation of volumes, with the highest deviation being observed for both validation phases at the daily and monthly timescales. In addition, an acceptable validation indicates that the calibrated parameter set is suitable for simulating flowrates at any point in the Corgo watershed. This is a very important outcome owing to the lack of flowrate measurements (only the ErmidaCorgo station is available for this watershed).

The model calibration for the Corgo watershed using a single meteorological station achieved satisfactory results (Fig. 4). Although the deviation of volume $(D v)$ improved $(-2 \%)$, showing a very good approach in terms of water volume, the coefficient of determination $\left(R^{2}\right)$ and Nash-Sutcliffe model coefficient of efficiency $(E)$ decrease from 0.81 to 0.64 to approximately 0.67 and 0.34 , respectively. Besides these results for the Ermida-Corgo station, further considerations can be made for other locations within the watershed, representing different tributaries of the main channel. In fact, extracting the daily mean flowrates for the sub-watersheds 6, 18 and 29 (Fig. 1b), it is clear that the corresponding cumulative distribution functions encompass a much larger variation among sub-watersheds in the multi-point run than in the single-station run (Fig. 5). While in the single-station run the daily mean flowrates mainly reflect differences in the sub-watershed areas, in the multi-point run there is a clear integration of diverse meteorological information. Hence, the single-station run clearly results in a poor simulation of the observed values when compared to the multi-point run (i.e. using PT.P.HRES, PT.TN.HRES, PT.TX.HRES and PT.TG.HRES).

\subsection{Flash flood assessment}

The model output response against precipitation is illustrated for four different flash floods, driven by either long or short-duration precipitation events (Fig. 6). A thorough examination of Fig. 6a shows a more reliable response of simulated flowrate to precipitation than the observed flowrate. As rain persistently fell, the observed flowrate shows irregular behavior, as it decreases after the third day of precipitation and only increases again after five days, right before the next high precipitation event (18 December 1958). As for the simulated flow, it shows a good response to precipitation, as it increases gradually with precipitation occurrence, reaching its highest value just before rainfall weakens and eventually ceases. Conversely, Fig. 6b illustrates an almost perfect response of both the observed and simulated flows against precipitation. The observed flowrate peak occurs one day earlier, but the falling hydrograph curve 

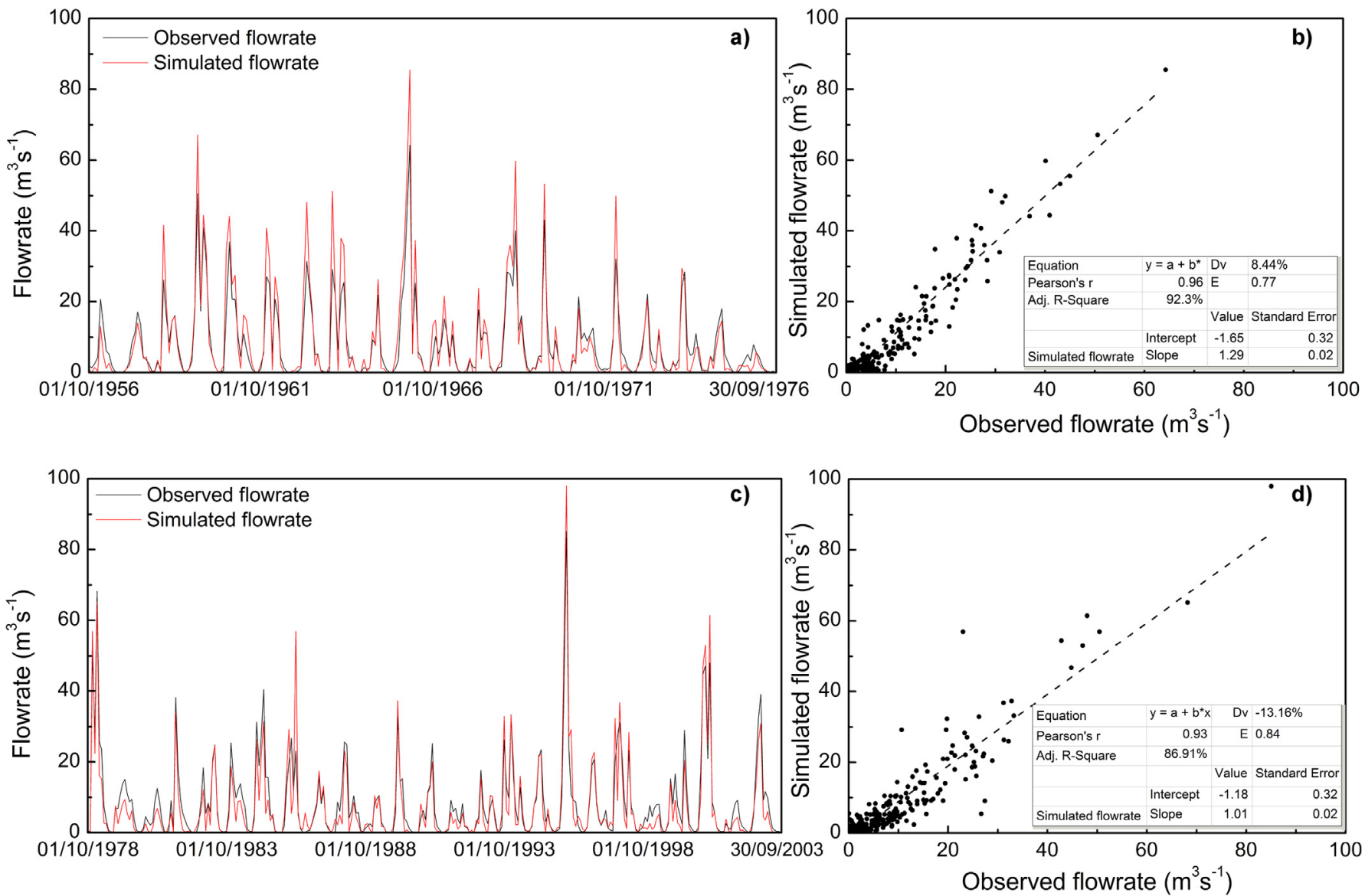

Fig. 3. (a, c) Chronograms and (b, d) scatterplots of the observed and HSPF simulated monthly mean flowrates at the Ermida-Corgo station and for the (a, b) calibration and (c, d) validation periods.

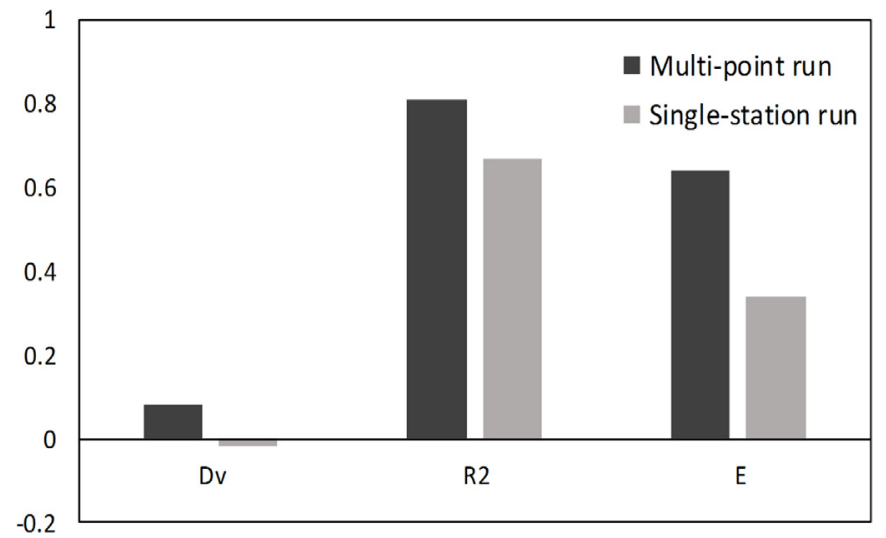

Fig. 4. Bar chart of the values for the statistical criteria obtained from the multi-point and single-station runs of HSPF (Dv - deviation of volumes; R2 - RSquared; E - Nash-Sutcliffe coefficient of efficiency).

drops much faster than the simulated flowrate curve. The above-described flash flood events hint at the difficulty in simulating extreme conditions, though HSPF performs reasonably well. Furthermore, the observed flowrates also comprise instrumental and other observational errors, which cannot be easily isolated, but may underlie some important discrepancies between observed and simulated curves.

\section{Conclusions}

In order to illustrate the applicability of these very high-resolution datasets to hydrologic simulations, the Corgo River flowrate was simulated by HSPF. The simulated daily mean flowrates compared well to the observed data on both daily and monthly timescales, according to the statistical criteria presented. Model validation also demonstrates a good representation of the observed data, graphically and statistically. Therefore, the hydrologic simulations provided in this study demonstrate that the model can achieve much higher performances by using a very high-resolution dataset, rather data using local meteorological stations.

The synergies resulting from coupling hydrologic modeling with very high-resolution datasets, particularly in watersheds with scarce observations, makes this approach useful to many other regions worldwide. In fact, providing decision-makers with accurate tools to assess hydrologic responses to climate behavior is of foremost relevance for water management, environmental protection and sustainability, as well as for risk assessments, such as risks of floods or droughts. In a forthcoming study we aim at reconstructing flowrates at several watersheds in Portugal, for time periods without hydrologic observations, and their subsequent comparison with historical flood occurrences (Fragoso et al., 2015; Santos et al., 2015b). These assessments are also important under climate change projections, so that the corresponding detrimental impacts can be properly mitigated through timely and suitable adaptation measures. In addition, the very high-resolution climatological dataset over Portugal, produced within the present study, can be applied not only to hydrologic simulations, but also to a wide range of areas of research, such as in agricultural and forestry systems, which have been shown to be under pressure by climate change projections in Portugal (Costa et al., 2016; Fraga et al., 2016a, 2016b; Santos et al., 2017a). The resulting knowledge can input decision support systems to provide guidelines to stakeholders and policymakers of economically relevant socioeconomic sectors. 

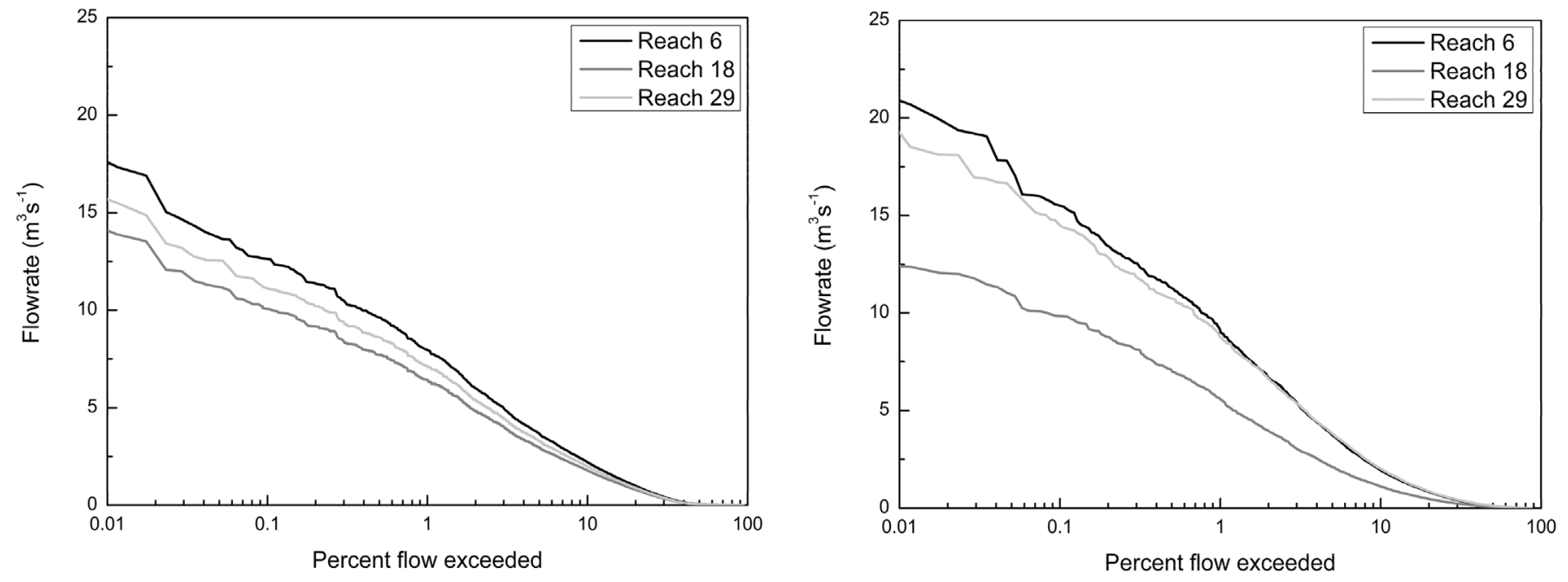

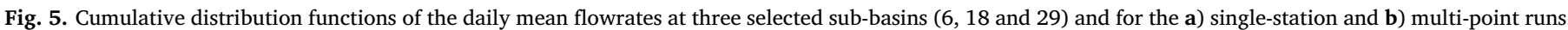
See Fig. 2b for sub-basin locations.
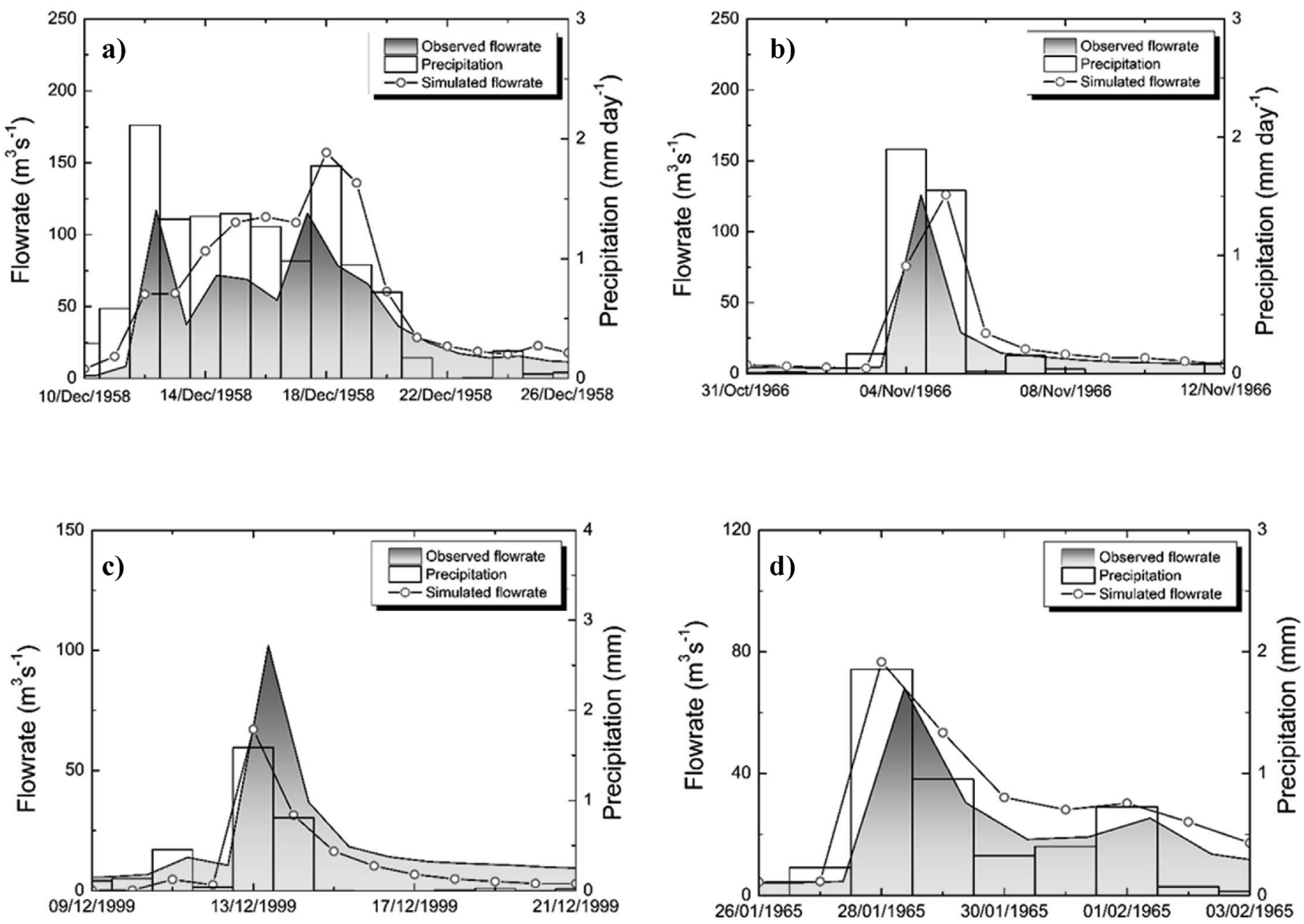

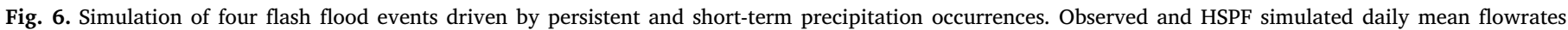
(curves), along with daily precipitation amounts (bars). 


\section{Acknowledgments}

This study was undertaken within the R\&D project INTERACT Integrative Research in Environment, Agro-Chain and Technology, in its research line BEST, NORTE-01-0145-FEDER-000017, co-funded by FEDER/NORTE 2020 (Programa Operacional Regional do Norte 2014/ 2020). It was also supported by FEDER/COMPETE/POCI - Operational Competitiveness and Internationalization Programme, POCI-01-0145FEDER-006958, and by FCT - Portuguese Foundation for Science and Technology, UID/AGR/04033/2013.

\section{Appendix A. Supplementary data}

Supplementary data related to this article can be found at http://dx. doi.org/10.1016/j.pce.2018.06.001.

\section{References}

Andrade, C., Fraga, H., Santos, J.A., 2014. Climate change multi- model projections for temperature extremes in Portugal. Atmos. Sci. Lett. 15 (2), 149-156. http://dx.doi. org/10.1002/asl2.485.

Andrade, C., Leite, S.M., Santos, J.A., 2012. Temperature extremes in Europe: overview of their driving atmospheric patterns. Nat. Hazards Earth Syst. Sci. 12 (5), 1671-1691. http://dx.doi.org/10.5194/nhess-12-1671-2012.

Azorin-Molina, C., Vicente-Serrano, S.M., McVicar, T.R., Jerez, S., Sanchez-Lorenzo, A., López-Moreno, J.-I., Revuelto, J., Trigo, R.M., Lopez-Bustins, J.A., Espírito-Santo, F., 2014. Homogenization and assessment of observed near-surface wind speed trends over Spain and Portugal, 1961-2011. J. Clim. 27 (10), 3692-3712.

Belo-Pereira, M., Dutra, E., Viterbo, P., 2011. Evaluation of global precipitation data sets over the Iberian Peninsula. J. Geophys. Res. Atmos. 116 (D20).

Bergman, M., Green, W., Donnangelo, L., 2002. Calibration of Storm Loads in the South Prong Watershed, Florida, Using WATERSHEDS/HSPF. Wiley Online Library.

Bicknell, B., Imhoff, J., Kittle Jr., J., Jobes, T., Donigian Jr., A., Johanson, R., 2001. Hydrological simulation program-FORTRAN: HSPF Version 12 User's manual. In: AQUA TERRA Consultants. Cooperation with the US Geological Survey and US Environmental Protection Agency, Mountain View, CA.

Bicknell, B.R., 2000. Watersheds Technical Note 6: Estimating Hydrology and Hydraulic Parameters for HSPF.

Bleecker, M., DeGloria, S., Hutson, J., Bryant, R., Wagenet, R., 1995. Mapping atrazine leaching potential with integrated environmental databases and simulation models. $\mathrm{J}$ Soil Water Conserv. 50 (4), 388-394.

Ciach, G.J., 2003. Local random errors in tipping-bucket rain gauge measurements. J. Atmos. Ocean. Technol. 20 (5), 752-759.

Costa, A.C., Santos, J.A., Pinto, J.G., 2012. Climate change scenarios for precipitation extremes in Portugal. Theor. Appl. Climatol. 108 (1-2), 217-234.

Costa, R., Fraga, H., Fernandes, P.M., Santos, J.A., 2016. Implications of future bioclimatic shifts on Portuguese forests. Reg. Environ. Change 1-11. http://dx.doi.org/10. 1007/s10113-016-0980-9.

Crawford, N.H., Linsley, R.K., 1966. Digital Simulation in Hydrology'Stanford Watershed Model 4.

Donigian, A., 2002. Watershed model calibration and validation: the HSPF experience. Proc. Water Environ. Fed. 2002 (8), 44-73.

Donigian, A., Davis, H., 1978. Agricultural Runoff Management (ARM): Users Manual.

Donigian, A.S., Crawford, N.H., 1976. Modeling Nonpoint Pollution from the Land Surface. US Environmental Protection Agency, Office of Research and Development, Environmental Research Laboratory.

Donigian, A.S., Huber, W.C., 1991. Modeling of Nonpoint Source Water Quality in Urban and Non-urban Areas. Environmental Research Laboratory, Office of Research and Development, US Environmental Protection Agency.

Donigian Jr., A., Bicknell, B., Imhoff, J., Singh, V., 1995. Hydrological simulation program-fortran (HSPF). In: Computer Models of Watershed Hydrology, pp. 395-442.

Duncker, J.J., Melching, C.S., 1998. Regional Rainfall-runoff Relations for Simulation of Streamflow for Watersheds in Du Page County. Illinois.

El-Sadek, A., Bleiweiss, M., Shukla, M., Guldan, S., Fernald, A., 2011. Alternative climate data sources for distributed hydrological modelling on a daily time step. Hydrol. Process. 25 (10), 1542-1557.

Fonseca, A., Ames, D.P., Yang, P., Botelho, C., Boaventura, R., Vilar, V., 2014. Watershed model parameter estimation and uncertainty in data-limited environments. Environ. Model. Software 51, 84-93.

Fonseca, A., Botelho, C., Boaventura, R., Vilar, V., 2015. Global warming effects on faecal coliform bacterium watershed impairments in Portugal. River Res. Appl. 31 (10), 1344-1353.

Fonseca, A., Fernandes, L.S., Fontainhas-Fernandes, A., Monteiro, S., Pacheco, F., 2016 From watershed to fish: impact of anthropogenic pressures on gill histopathology. Sci. Total Environ. 550, 972-986.

Fonseca, A., Boaventura, R.A.R., Vilar, V.J.P., 2017. Integrating water quality responses to best management practices in Portugal. Environ. Sci. Pollut. Control Ser. 1-10 Springer.

Fonseca, A.R., Santos, J.A., 2017. High-resolution temperature datasets in Portugal from a geostatistical approach: variability and extremes. J. Appl. Meteorol. Climatol.(2017).

Fraga, H., Santos, J.A., Malheiro, A.C., Oliveira, A.A., Moutinho-Pereira, J., Jones, G.V., 2016a. Climatic suitability of Portuguese grapevine varieties and climate change adaptation. Int. J. Climatol. 36 (1), 1-12. http://dx.doi.org/10.1002/joc.4325.

Fraga, H., Santos, J.A., Moutinho-Pereira, J., Carlos, C., Silvestre, J., Eiras-Dias, J., Mota, T., Malheiro, A.C., 2016b. Statistical modelling of grapevine phenology in Portuguese wine regions: observed trends and climate change projections. J. Agric. Sci. 154 (5), 795-811. http://dx.doi.org/10.1017/S0021859615000933.

Fragoso, M., Marques, D., Santos, J.A., Alcoforado, M.J., Amorim, I., Garcia, J.C., Silva, L., de Fátima Nunes, M., 2015. Climatic extremes in Portugal in the 1780s based on documentary and instrumental records. Clim. Res. 66 (2), 141-159.

Haylock, M., Hofstra, N., Klein Tank, A., Klok, E., Jones, P., New, M., 2008. A European daily high-resolution gridded data set of surface temperature and precipitation for 1950-2006. J. Geophys. Res. Atmospheres 113 (D20).

Hofstra, N., Haylock, M., New, M., Jones, P.D., 2009. Testing E-OBS European high-resolution gridded data set of daily precipitation and surface temperature. J. Geophys. Res. Atmos. 114 (D21).

Hughes, D.A., Slaughter, A., 2015. Daily disaggregation of simulated monthly flows using different rainfall datasets in southern Africa. J. Hydrol.: Reg. Stud. 4, 153-171.

Hummel, P., Kittle Jr., J., Gray, M., 2001. Wdmutil-a Tool for Managing Watershed Modeling Time-series Data: User's Manual. US EPA Office of Water, Washington DC.

Kohler, M., Nordenson, T., Fox, W., 1955. Evaporation from Pans and Lakes: US Weather Bureau Research Paper 38. US Weather Bureau, Washington, DC.

Kouwen, N., Danard, M., Bingeman, A., Luo, W., Seglenieks, F.R., Soulis, E.D., 2004. Case study: watershed modeling with distributed weather model data. J. Hydrol. Eng. 10 (1), 23-38.

Lian, Y., Chan, I.-C., Singh, J., Demissie, M., Knapp, V., Xie, H., 2007. Coupling of hydrologic and hydraulic models for the Illinois River watershed. J. Hydrol. 344 (3), 210-222.

Mehta, V.K., Walter, M.T., Brooks, E.S., Steenhuis, T.S., Walter, M.F., Johnson, M., Boll, J., Thongs, D., 2004. Application of SMR to modeling watersheds in the catskill mountains. Environ. Model. Assess. 9 (2), 77-89.

Nash, J.E., Sutcliffe, J.V., 1970. River flow forecasting through conceptual models part I-a discussion of principles. J. Hydrol. 10 (3), 282-290.

Obled, C., Wendling, J., Beven, K., 1994. The sensitivity of hydrological models to spatial rainfall patterns: an evaluation using observed data. J. Hydrol. 159 (1-4), 305-333.

Penman, H.L., 1948. Natural evaporation from open water, bare soil and grass. In: Paper Presented at the Proceedings of the Royal Society of London A: Mathematical, Physical and Engineering Sciences.

Santos, J., Corte-Real, J., Leite, S., 2005. Weather regimes and their connection to the winter rainfall in Portugal. Int. J. Climatol. 25 (1), 33-50.

Santos, J., Corte-Real, J., 2006. Temperature extremes in Europe and wintertime largescale atmospheric circulation: HadCM3 future scenarios. Clim. Res. 31 (1), 3-18. http://dx.doi.org/10.3354/Cr031003.

Santos, J., Corte-Real, J., Ulbrich, U., Palutikof, J., 2007. European winter precipitation extremes and large-scale circulation: a coupled model and its scenarios. Theor. Appl. Climatol. 87 (1), 85-102.

Santos, J.A., Woollings, T., Pinto, J.G., 2013. Are the winters 2010 and 2012 archetypes exhibiting extreme opposite behavior of the North Atlantic jet stream? Mon. Weather Rev. 141 (10), 3626-3640. http://dx.doi.org/10.1175/Mwr-D-13-00024.1.

Santos, J.A., Pfahl, S., Pinto, J.G., Wernli, H., 2015a. Mechanisms underlying temperature extremes in Iberia: a Lagrangian perspective. Tellus Series A Dyn. Meteorol. Oceanogr. 67, 26032. http://dx.doi.org/10.3402/Tellusa.V67.26032.

Santos, M., Santos, J.A., Fragoso, M., 2015b. Historical damaging flood records for 18712011 in Northern Portugal and underlying atmospheric forcings. J. Hydrol. 530, 591-603. http://dx.doi.org/10.1016/j.jhydrol.2015.10.011.

Santos, J.A., Belo-Pereira, M., Fraga, H., Pinto, J.G., 2016. Understanding climate change projections for precipitation over western Europe with a weather typing approach. J. Geophys. Res. Atmos. 121 (3), 1170-1189. http://dx.doi.org/10.1002/ 2015JD024399.

Santos, J.A., Costa, R., Fraga, H., 2017a. Climate change impacts on thermal growing conditions of main fruit species in Portugal. Climatic Change 140 (2), 273-286. http://dx.doi.org/10.1007/s10584-016-1835-6.

Santos, M., Santos, J.A., Fragoso, M., 2017b. Atmospheric driving mechanisms of flash floods in Portugal. Int. J. Climatol. 37 (S1), 671-680.

Schuol, J., Abbaspour, K., 2007. Using monthly weather statistics to generate daily data in a SWAT model application to West Africa. Ecol. Model. 201 (3), 301-311.

Shrestha, R., Tachikawa, Y., Takara, K., 2004. Performance analysis of different meteorological data and resolutions using MaScOD hydrological model. Hydrol. Process. 18 (16), 3169-3187.

Tavares Wahren, F., Julich, S., Nunes, J.P., Gonzalez-Pelayo, O., Hawtree, D., Feger, K.H., Keizer, J.J., 2016. Combining digital soil mapping and hydrological modeling in a data scarce watershed in north-central Portugal. Geoderma 264 (Part B), 350-362. https://doi.org/10.1016/j.geoderma.2015.08.023.

Vieira, J., Fonseca, A., Vilar, V.J., Boaventura, R.A., Botelho, C.M., 2012. Water quality in Lis river, Portugal. Environ. Monit. Assess. 184 (12), 7125-7140.

Vieira, J., Fonseca, A., Vilar, V.J., Boaventura, R.A., Botelho, C.M., 2013. Water quality modelling of Lis river, Portugal. Environ. Sci. Pollut. Control Ser. 20 (1), 508-524.

White, C.J., Tanton, T.W., Rycroft, D.W., 2014. The impact of climate change on the water resources of the Amu Darya watershed in central Asia. Water Resour. Manag. 28 (15), 5267-5281.

Zhang, J., Ross, M., Trout, K., Zhou, D., 2009. Calibration of the HSPF model with a new coupled FTABLE generation method. Prog. Nat. Sci. 19 (12), 1747-1755. https://doi. org/10.1016/j.pnsc.2009.07.006. 